\title{
A case report of the pancreatic and periampullary metastases of renal cell carcinoma, 17 years after surgery
}

\author{
Ruiling Lu ${ }^{1}$, Ying Ying ${ }^{2}$, Zhenhua Zhu ${ }^{1}$, Hongping Wan ${ }^{3}$, Guohua Li ${ }^{1}, \mathrm{Xu} \mathrm{Shu}^{1}$, Wangdi Liao ${ }^{1}$ \\ ${ }^{1}$ Department of Gastroenterology, the First Affiliated Hospital of Nanchang University, Nanchang, China; ${ }^{2}$ Jiangxi Institute of Respiratory Disease, \\ The First Affiliated Hospital of Nanchang University, Nanchang, China; ${ }^{3}$ Department of Pathology, the First Affiliated Hospital of Nanchang \\ University, Nanchang, China \\ Correspondence to: Wangdi Liao, PhD, MD. Department of Gastroenterology, the First Affiliated Hospital of Nanchang University, 17 Yongwai \\ Zheng Street, Donghu District, Nanchang 330006, China. Email: lwd1990@126.com.
}

\begin{abstract}
Renal cell carcinoma (RCC) is the most common renal tumor with a high incidence in the recent decade. Generally, an RCC metastasis mainly occurs via hematogenous and lymphomatous routes. Even though RCC has a potential to metastasize to almost any site, metastasis to the pancreas and duodenal ampulla is a rare event. In this study, we describe a case of pancreatic and periampullary metastatic renal cell carcinoma, which recurred 17 years after surgery. The patient admitted to hospital for severe symptoms of jaundice and skin pruritus after removal of the primary tumor for 17 years. Computer tomography angiography (CTA) scan and endoscopy showed pancreatic and duodenal ampullary metastasis. Finally, it confirmed by histopathologic examination. After some symptomatic treatment has been given the patient remained alive. However, intermittent hematochezia along with these metastatic lesions continue to occur until now as observed during the annual follow-up appointments. This study concludes that metastatic involvement of the pancreas and other organs should be suspected in any patient with a history of an RCC who does not manifest any typical symptom even after more than 10 years of RCC resection. In the case of abnormal symptoms and examination results after several years of RCC surgery, attention should be paid to provide immediate treatment.
\end{abstract}

Keywords: Renal cell carcinoma (RCC); periampullary metastasis; secondary malignant tumor; case report

Submitted Jul 01, 2021. Accepted for publication Aug 04, 2021.

doi: $10.21037 /$ tcr-21-1137

View this article at: https://dx.doi.org/10.21037/tcr-21-1137

\section{Introduction}

Renal cell carcinoma (RCC) is the most common renal tumor, accounting for $2-3 \%$ of all malignancies and $77.24 \%$ of all urological malignancies (1). In recent years, the incidence of an RCC is increasing in China (1). An RCC usually causes only a few early symptoms, which are often nonspecific. An RCC spreads in the whole body through the blood and lymphatic vessels, especially in the form of multiple metastases. Among them, lung metastasis is the most common, followed by liver, bone, and adrenal gland metastases (2). However, duodenal ampullary metastasis is rare.

In this paper, we describe a patient who developed a pancreatic recurrence of an RCC at 17 years after radical resection of an RCC and 1 year later had a duodenal ampullary metastasis. We present the following article in accordance with the CARE reporting checklist (available at https://dx.doi.org/10.21037/tcr-21-1137).

\section{Case presentation}

A 71-year-old female patient was admitted to our gastroenterology department for severe symptoms of jaundice and skin pruritus on September 1, 2017. A color doppler ultrasound conducted in another hospital showed an abdominal mass, dilated bile duct, and enlarged gallbladder. Her medical history revealed that she had undergone right nephrectomy for renal clear cell carcinoma 17 years ago. The clinical stage of RCC with Fuhrman 


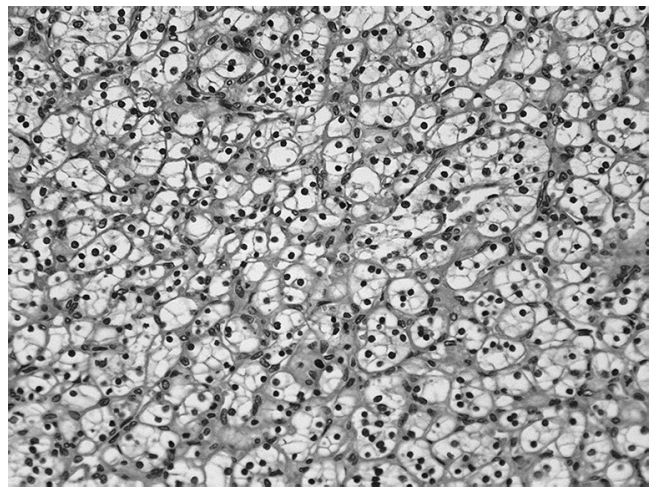

Figure 1 Biopsy of primary tumor with histology. Microscopic appearance of original primary demonstrates typical histological findings for clear cell carcinoma (HE, $\times 100)$.
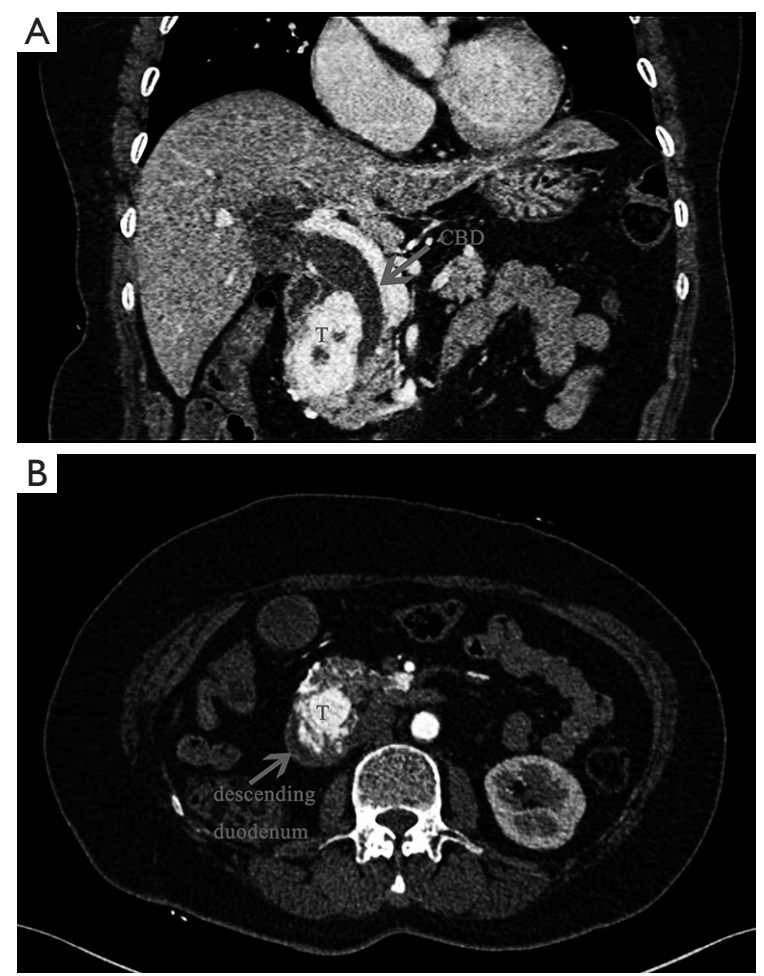

Figure 2 Abdominal computed tomographic scan at the time of initial visit. (A) Coronal contrast-enhanced CT image shows a pancreatic head tumor oppressing the lower end of the common bile duct (CBD) and secondary dilatation of CBD. (B) Axial contrast-enhanced CT image shows a blurred boundary between the pancreatic head tumor and the descending duodenum and the descending duodenal lumen tightly compressed by the tumor. grade 3 (Figure 1) was stage I (T1b, N0, and M0), according to Tumor, Node, Metastasis (TNM) classification. Chemotherapy and immunotherapy were not given after surgery. On physical examination at admission, the patient exhibited red papules along with multiple scratches, without icteric sclera, all over the body. Moreover, superficial lymph nodes were not touched, the abdomen was soft, and a $15 \mathrm{~cm}$ surgical scar was present on the right side of the patient's waist. The liver and the gallbladder were not touched under the costal margin, and the gallbladder did not show any tenderness. Laboratory findings were as follows: ALP 27 U/L, AST 38 U/L, TBIL $260.8 \mu \mathrm{mol} / \mathrm{L}$, DBIL $202.9 \mu \mathrm{mol} / \mathrm{L}$, and GGT $453 \mathrm{U} / \mathrm{L}$. An abdominal CTA scan showed several mass with marked enhancement in the liver (the largest one was $2.3 \mathrm{~cm} \times 2.7 \mathrm{~cm}$ in size); moreover, a tumor with a size of $6.6 \mathrm{~cm} \times 4.8 \mathrm{~cm} \times 6.4 \mathrm{~cm}$ was found at the head of the pancreas. Additionally, choledochectasia was observed. No enlarged lymph nodes were detected (Figure 2A,B). She refused to receive an operation but had undergone endoscopic insertion of biliary stents (Figure 3). However, after the operation, she felt symptom remission. In the following year, she underwent endoscopic insertions of biliary stents twice to relieve jaundice, which occurred due to in-stent restenosis.

On October 5, 2018, the patient was hospitalized due to hematochezia. Axial contrast-enhanced computer tomography (CT) image shows the blurred boundary between the pancreatic head tumor and the descending duodenum, the descending duodenal lumen tightly compressed by the tumor, and part of the tumor protruded into the descending duodenal lumen (Figure 4). Thereafter, she underwent upper gastrointestinal endoscopy, which showed a mass above the duodenal papilla. A sample of the mass was withdrawn for biopsy (Figure 5). Histopathologic examination revealed a metastatic RCC, being consistent with metastasis of the RCC recognized 18 years ago (Figure 6).

On May 9, 2019, the patient was admitted again because of hematochezia. When she underwent gastroscopy, we found the protuberant lesion became bigger than before, which caused a duodenal obstruction. Therefore, we placed a duodenal stent (Figure $7 A, B$ ). The patient remained alive. However, intermittent hematochezia along with these metastatic lesions continue to occur until now as observed during the annual follow-up appointments. 


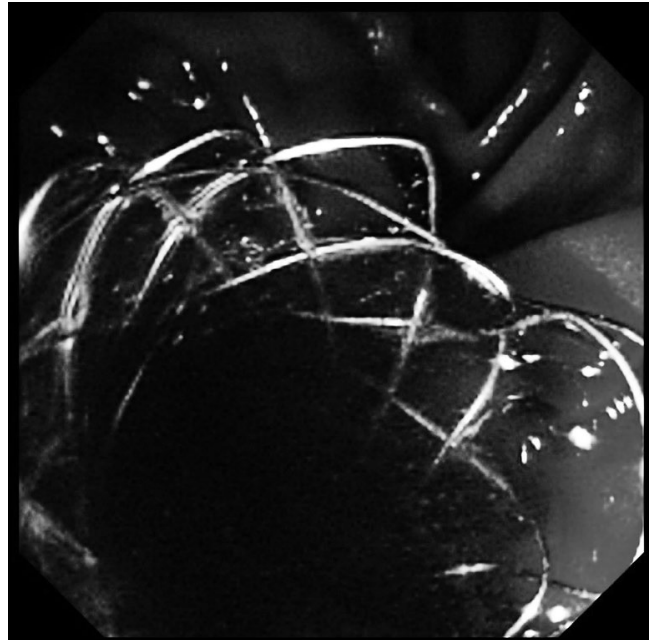

Figure 3 Endoscopic retrograde cholangiopancreatography (ERCP) examination on September 1, 2017. A metal biliary stent $(10 \mathrm{~mm} \times 60 \mathrm{~mm})$ is placed in the common bile duct through upper gastrointestinal endoscopy.

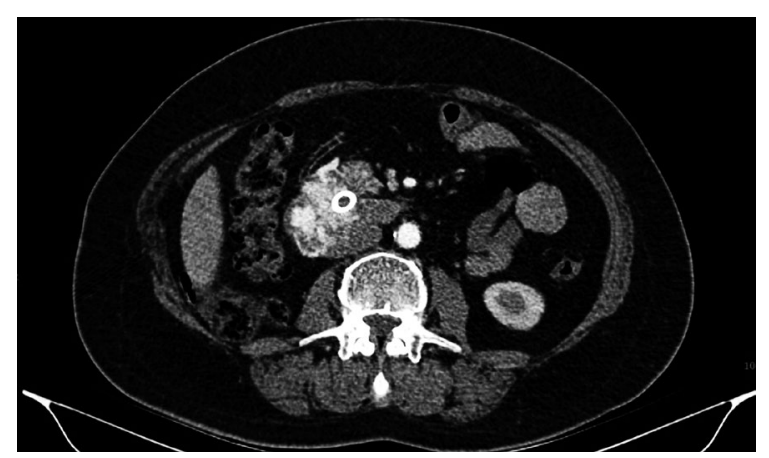

Figure 4 Abdominal computed tomographic scan on October 5, 2018. An axial contrast-enhanced CT image obtained 1 year after placement of the biliary stent shows some enlargement of the pancreatic head tumor and part of the tumor protruding into the descending duodenal lumen.

All procedures performed in studies involving human participants were in accordance with the ethical standards of the institutional and/or national research committee(s) and with the Helsinki Declaration (as revised in 2013). Written in-formed consent was obtained from the patient.

\section{Discussion}

In the present case report, we observed an uncommon clinical behavior of an RCC. Clear cell RCC showed potential to relapse beyond 10 years after surgery (3). Recurrence of

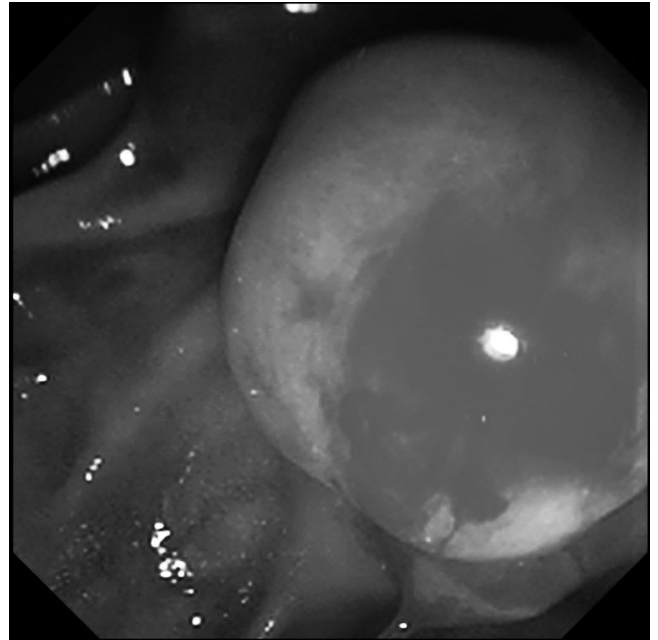

Figure 5 Gastroscopic examination on October 9, 2018. Endoscopic examination shows a protuberant lesion, about $4 \mathrm{~cm}$ long, at the side of the stent.

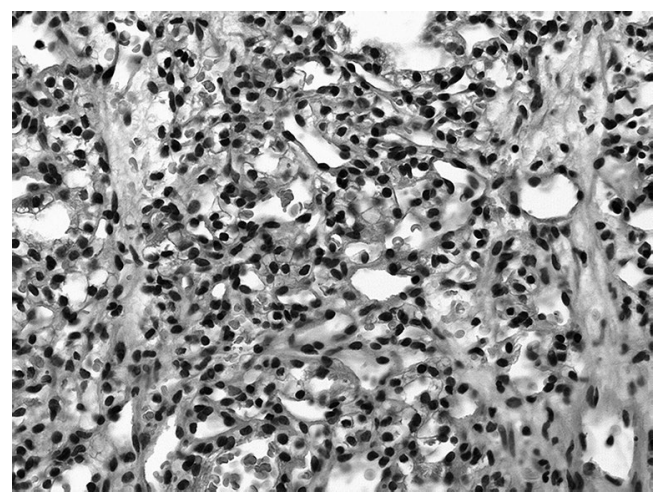

Figure 6 Biopsy of mass with histology. Microscopic appearance of periampullary metastasis demonstrates typical histological findings for clear cell carcinoma $(\mathrm{HE}, \times 200)$.

tumors at typical sites decreased, whereas retroperitoneal organ recurrence increased in a time-dependent manner, with a pancreatic metastatic rate of $2.7 \%$ (3). A periampullary metastasis from an RCC is reported to be sporadic, which is found only in 19 cases, including the present one (4-19). Perambulator metastases ordinarily emerges acute or chronic gastrointestinal hemorrhage (13/19), duodenal obstruction (4/19), duodenal ulcer (1/19), or obstructive jaundice (1/19). Diagnosis of duodenal metastases as a cause of gastrointestinal bleeding is a challenge due to its rarity and lack of typical clinical characteristics.

The findings of the present case study, along with some other studies, indicated that most of the duodenal metastasis 

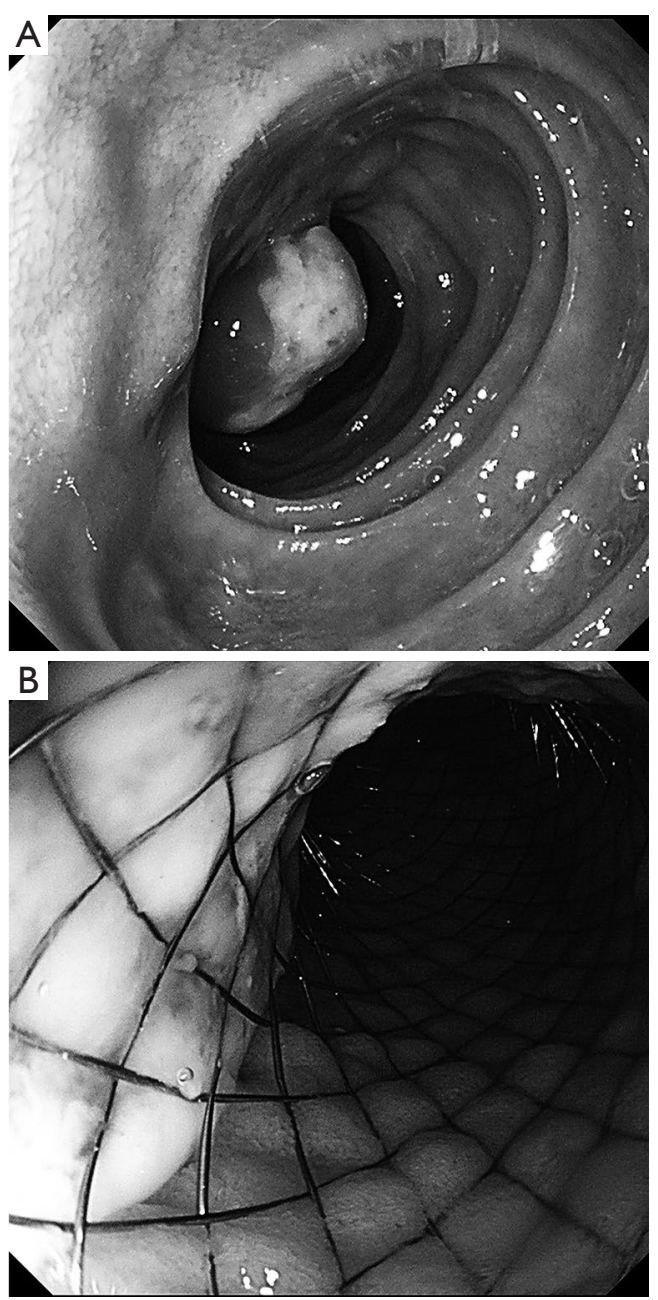

Figure 7 Gastroscopic examination on May 9, 2019. Endoscopic examination shows an $8 \mathrm{~cm}$ protuberant lesion causing a duodenal obstruction (A) and placement of a duodenal stent $(22 \mathrm{~mm} \times$ $120 \mathrm{~mm})(\mathrm{B})$.

of an RCC occurs after right kidney nephrectomy. However, the mechanism is poorly understood. Synchronous metastases of an RCC to the duodenum and pancreas were a rare phenomenon in most patient (20). In the present case, due to the patient's rejection of surgical treatment, the duodenal renal cell metastasis from the secondary pancreatic malignant tumor cannot be confirmed. Otherwise, pancreatic metastases are usually asymptomatic, accompanied by abdominal pain, weight loss and other common symptoms, often overlooked by patients. However, after the clinical examinations, we find that the metastasis may have spread.

For any RCC patient with pancreatic or duodenal metastasis, if feasible in medicine and technology, surgery is the best option to choose, because it seems to prolong the disease-free survival $(4,20)$. However, multiple metastatic lesions carry a worse prognosis than solitary ones (4). Previous studies have found that the average survival time of patients with disseminated malignant tumors is about 4 months, and generally, only $10 \%$ of them can survive for 1 year (4). However, in the present case study, the patient still survived for 4 years after the detection of metastases. The reason is unclear and needs further study. The case draws attention to an essential aspect of the biological behavior of an RCC. This type of tumor is often a slowgrowing lesion and may be associated with a late onset of solitary metastases that may occur even after more than 10 years after the removal of the primary tumor. In the case of abnormal symptoms and examination results after several years of RCC surgery, attention should be paid to provide immediate treatment.

\section{Conclusions}

The present case study indicates that an RCC can cause metastases without any typical symptom even after more than 10 years of primary tumor surgery. This study also highlights the necessity of monitoring patients with an RCC for preventing any further cost and loss of life.

\section{Acknowledgments}

We especially thank the patient for allowing us to publish this case report.

Funding: This work was supported by the National Natural Science Foundation of China (No. 81960110).

\section{Footnote}

Reporting Checklist: The authors have completed the CARE reporting checklist. Available at https://dx.doi. org/10.21037/tcr-21-1137

Peer Review File: Available at https://dx.doi.org/10.21037/ tcr-21-1137

Conflicts of Interest: All authors have completed the ICMJE uniform disclosure form (available at https://dx.doi. org/10.21037/tcr-21-1137). The authors have no conflicts of interest to declare.

Ethical Statement: The authors are accountable for all aspects 
of the work in ensuring that questions related to the accuracy or integrity of any part of the work are appropriately investigated and resolved. All procedures performed in studies involving human participants were in accordance with the ethical standards of the institutional and/or national research committee(s) and with the Helsinki Declaration (as revised in 2013). Written informed consent was obtained from the patient for publication of this case report and accompanying images. A copy of the written consent is available for review by the editorial office of this journal.

Open Access Statement: This is an Open Access article distributed in accordance with the Creative Commons Attribution-NonCommercial-NoDerivs 4.0 International License (CC BY-NC-ND 4.0), which permits the noncommercial replication and distribution of the article with the strict proviso that no changes or edits are made and the original work is properly cited (including links to both the formal publication through the relevant DOI and the license). See: https://creativecommons.org/ licenses/by-nc-nd/4.0/.

\section{References}

1. Liu SZ, Guo LW, Cao XQ, et al. Estimation on the incidence and mortality of kidney cancer in China, in 2014. Zhonghua Liu Xing Bing Xue Za Zhi 2018;39:1346-50.

2. Psutka SP, Master VA. Role of metastasis-directed treatment in kidney cancer. Cancer 2018;124:3641-55.

3. Noguchi G, Nakaigawa N, Taguri M, et al. Timedependent change in relapse sites of renal cell carcinoma after curative surgery. Clin Exp Metastasis 2018;35:69-75.

4. Espinoza E, Hassani A, Vaishampayan U, et al. Surgical excision of duodenal/pancreatic metastatic renal cell carcinoma. Front Oncol 2014;4:218.

5. Vootla VR, Kashif M, Niazi M, et al. Recurrent Renal Cell Carcinoma with Synchronous Tumor Growth in Azygoesophageal Recess and Duodenum: A Rare Cause of Anemia and Upper Gastrointestinal Bleeding. Case Rep Oncol Med 2015;2015:143934.

6. Rustagi T, Rangasamy P, Versland M. Duodenal bleeding from metastatic renal cell carcinoma. Case Rep Gastroenterol 2011;5:249-57.

7. Cherian SV, Das S, Garcha AS, et al. Recurrent renal cell cancer presenting as gastrointestinal bleed. World J Gastrointest Oncol 2011;3:99-102.

8. Geramizadeh B, Mostaghni A, Ranjbar Z, et al. An unusual case of metastatatic renal cell carcinoma presenting as melena and duodenal ulcer, 16 years after nephrectomy; a case report and review of the literature. Iran J Med Sci 2015;40:175-80.

9. Toh SK, Hale JE. Late presentation of a solitary metastasis of renal cell carcinoma as an obstructive duodenal mass. Postgrad Med J 1996;72:178-9.

10. Omranipour R, Mahmoud Zadeh H, Ensani F, et al. Duodenal Metastases From Renal Cell Carcinoma Presented With Melena: Review and Case Report. Iran J Pathol 2017;12:272-6.

11. Lynch-Nyhan A, Fishman EK, Kadir S. Diagnosis and management of massive gastrointestinal bleeding owing to duodenal metastasis from renal cell carcinoma. J Urol 1987;138:611-3.

12. Bhatia A, Das A, Kumar Y, et al. Renal cell carcinoma metastasizing to duodenum: a rare occurrence. Diagn Pathol 2006;1:29.

13. Imam MH, Gossard AA, Sinakos E, et al. Pathogenesis and management of pruritus in cholestatic liver disease. J Gastroenterol Hepatol 2012;27:1150-8.

14. Hsu CC, Chen JJ, Changchien CS. Endoscopic features of metastatic tumors in the upper gastrointestinal tract. Endoscopy 1996;28:249-53.

15. Le Borgne J, Partensky C, Glemain P, et al. Pancreaticoduodenectomy for metastatic ampullary and pancreatic tumors. Hepatogastroenterology 2000;47:540-4.

16. Freedman AI, Tomaszewski JE, Van Arsdalen KN. Solitary late recurrence of renal cell carcinoma presenting as duodenal ulcer. Urology 1992;39:461-3.

17. Loualidi A, Spooren PF, Grubben MJ, et al. Duodenal metastasis: an uncommon cause of occult small intestinal bleeding. Neth J Med 2004;62:201-5.

18. Black JA, Mendelson RM. Duodenal haemorrhage resulting from renal cell carcinoma metastases. Australas Radiol 1995;39:396-8.

19. Nabi G, Gandhi G, Dogra PN. Diagnosis and management of duodenal obstruction due to renal cell carcinoma. Trop Gastroenterol 2001;22:47-9.

20. Ma Y, Yang J, Qin K, et al. Resection of pancreatic metastatic renal cell carcinoma: experience and long-term survival outcome from a large center in China. Int J Clin Oncol 2019;24:686-93.

Cite this article as: Lu R, Ying Y, Zhu Z, Wan H, Li G, Shu $\mathrm{X}$, Liao $\mathrm{W}$. A case report of the pancreatic and periampullary metastases of renal cell carcinoma, 17 years after surgery. Transl Cancer Res 2021;10(10):4560-4564. doi: 10.21037/tcr-21-1137 